Nordic Concrete Research - Publ. No. NCR 62 - ISSUE 1 / 2020 - Article 6, pp. 107-124

\begin{tabular}{|c|c|}
\hline$S$ sciendo & 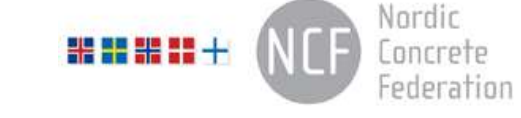 \\
\hline $\begin{array}{l}\text { (C) Article authors. This is an open access article distributed under } \\
\text { the Creative Commons Attribution-NonCommercial-NoDerivs } \\
\text { licens. (http://creaticecommons.org/licenses/by.nc-nd/3.0/). }\end{array}$ & $\begin{array}{l}\text { ISSN online } 2545-2819 \\
\text { ISSN print } \quad 0800-6377\end{array}$ \\
\hline DOI: $10.2478 /$ ncr-2020-0010 & $\begin{array}{r}\text { Received: Feb 19,2020 } \\
\text { Revision received: June 19, } 2020 \\
\text { Accepted: June 22, } 2020\end{array}$ \\
\hline
\end{tabular}

\title{
Activation Energy for the Concrete Maturity Model - Part 2: New Model for Temperature Dependent $\mathbf{E}_{\mathbf{a}}$
}

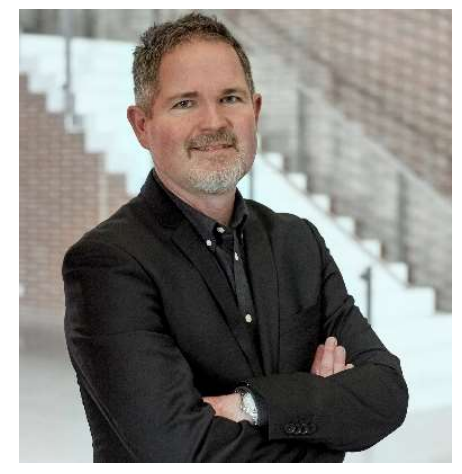

Claus Vestergaard Nielsen, M.Sc., Ph.D.

Concrete Expert, Danish Technological Institute

Gregersensvej, DK-2630 Taastrup

cln@teknologisk.dk

\begin{abstract}
The article addresses the modelling of the maturity of concrete. The apparent activation energy is the backbone of the Arrhenius model, which is typically used to model the maturity of concrete. The maturity (or the equivalent age) is influenced by the curing temperature and it is applied when modelling the hydration process and the hardening of concrete for instance in order to forecast the early-age strength to determine the time for removal of formwork or the time for prestressing. Part 1 of the article describes the background for the maturity model and the tests carried out as part of a large test programme at the DTI concrete lab. The tests were applying iso-thermal curing temperatures from $5^{\circ} \mathrm{C}$ to $60^{\circ} \mathrm{C}$ for various durations before measuring the compressive strength.
\end{abstract}

Part 2 of the article presents a model for the activation energy based on these test results. An alternative formulation of the maturity model is suggested and compared with other similar concrete tests found in the literature for early-age strengths. The alternative model is shown to give better accuracy when modelling the early-age strengths of concrete. The tests include five different concretes, using three different cement types and the addition of fly ash.

Key words: Activation energy, maturity, early-age strength, curing. 
Part 1 contains the background for the concrete maturity model and the description of a large test series undertaken at the DTI laboratory with different cement types and binder combinations. Reference is made to Part 1 for a thorough description of the different concretes, mix designs and the concrete constituents. The five different concretes included in the investigation have the following binder system compositions:

- Mix A: Based on 100\% CEM I 42.5 SR5

- Mix B: Based on 75\% CEM I 42.5 SR5 and 25\% fly ash

- Mix C: Based on 100\% CEM I 52.5

- Mix D: Based on 75\% CEM I 52.5 and 25\% fly ash

- Mix E: Based on 10\% slag cement CEM III/B 42.5

Part 2 of the article contains a refined maturity model based on the widely used Freiesleben Hansen and Pedersen (FHP) model [1]. This model is used extensively around the world and it is the basis for Eurocode 2 and the fib Model Code, refer to Part 1 for references. Part 2 also contains discussions of the results and a comparison with other reported tests in this field.

First the activation energy is calculated from the iso-thermal curing test results described in Part 1. Then the temperature dependency of the apparent activation energy $E_{a}$ is assessed and the original FHP model is modified to fit the results satisfactorily. In the present Part 2, references are made to the equations of Part 1 on the form (P1-x) where $\mathrm{x}$ is the equation number used in Part 1.

\section{2.}

\section{APPARENT ACTIVATION ENERGY ANALYSIS}

\section{1}

\section{Alternative model for temperature dependency}

In order to determine the most suitable value for the apparent activation energy that makes the iso-thermally cured samples match the reference values, a data fitting is carried out. Figures 1-3 show the measured rate factors for each test as a function of the curing temperature. The data points are obtained from the following procedure:

- First the average strength value measured at a given combination of age and curing temperature is converted into maturity age by means of the inverted version of (P1-6) and the parameters listed in Table 2 of Part 1 . This yields the maturity $M_{\text {test }}(T)$ for each test result.

- Secondly, the calculated maturity age is divided with the real curing time, yielding the rate factor $H_{\text {test }}(T)=M_{\text {test }}(T) / t_{\text {test }}$, which is plotted in the diagrams below.

The data shown in Figures 1-3 is based on early-age strength results up to a maturity of around 7 days. If results at later ages are included the scatter becomes massive and no clear conclusions are possible. The curing temperatures used in the calculations are nominal and not monitored temperatures.

In Figure 1 the results are depicted for the low curing temperatures. One observation that is clearly made is that mix E (slag cement) shows lower rate factor than the other mixes. At $5^{\circ} \mathrm{C}$ the difference is significant. The FHP model is seen to represent the average of all the results but in the 
following two alternative models are proposed in order to differentiate between the different concretes. One model is suggested for mixes A-D and a separate model for mix E.

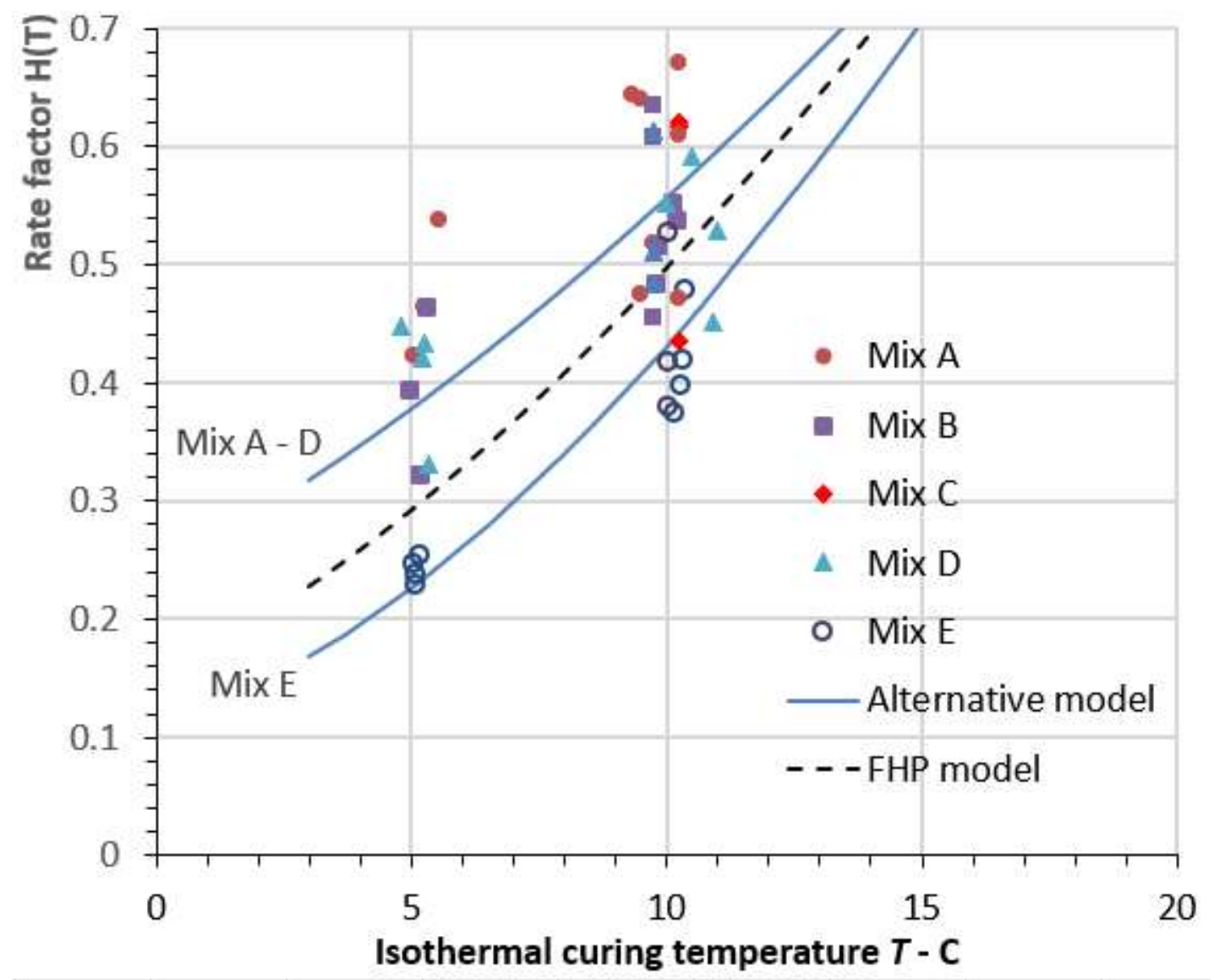

Figure 1 - Rate factor $H_{\text {test }}(T)$ for all concrete mixes for temperatures below $20^{\circ} \mathrm{C}$.

Figures 2 and 3 show the results for iso-thermal curing temperatures at $20^{\circ} \mathrm{C}$ and up to $60^{\circ} \mathrm{C}$. The dashed lines represent the FHP model in (P1-3) and the solid lines are the alternative models suggested in the following. The following observations are made:

- The experimental scatter is found to be very high, which makes a precise model difficult to find. One reason for the scatter is the logarithmic maturity scale that can make even small differences in strength observations result in significant differences in the rate factor (and thereby also in the apparent activation energy).

- The FHP model overpredicts the rate factor, especially for the temperatures above $30^{\circ} \mathrm{C}$. This is found for concrete mixes A to D whereas mix E seems to be in fairly good agreement with the FHP model.

In the following the alternative models, shown in Figures 1-3, are described. They are suggested firstly, in order to obtain a better correlation between the experimental observations and the model and secondly, to obtain a model prediction of early-age strengths that is slightly conservative.

Table 1 contains the alternative model parameters for the different concretes, corresponding to the solid lines shown in Figures 1-3. 
The alternative model is formulated as a modification of the bi-linear model by Freiesleben Hansen and Pedersen, previously shown as equation (P1-3) in Part 1. The modified version reads:

$$
E_{a}(T)= \begin{cases}E_{a 20}+K_{1}\left(20^{\circ} \mathrm{C}-T\right), & \text { for } T<T_{\mathrm{ref}} \\ E_{a 20}+K_{2}\left(20^{\circ} \mathrm{C}-T\right), & \text { for } T \geq T_{\mathrm{ref}}\end{cases}
$$

where the factor $K_{2}\left(\mathrm{~J} / \mathrm{mol} /{ }^{\circ} \mathrm{C}\right)$ is introduced for the temperatures above $T_{\text {ref. }}$ For the original FHP model in (P1-3) we have $E_{a 20}=33500 \mathrm{~J} / \mathrm{mol}, K_{1}=1470 \mathrm{~J} / \mathrm{mol} /{ }^{\circ} \mathrm{C}$ and $K_{2}=0$. Table 1 contains the input parameters for the alternative model fitted to the test results.

For mixes A and B, based on CEM I 42.5 N SR5, there seems to be a slightly higher rate factor when fly ash is included. This is opposite to what was suggested by others [2,3]. However, the statistical scatter makes it impossible to separate them and the same alternative model is suggested in Table 1 for all mixes A-D. The same can be said for mixes C and D, based on CEM I 52.5 N. The introduction of $K_{2}=300 \mathrm{~J} / \mathrm{mol} /{ }^{\circ} \mathrm{C}$ in Figure 2 is seen to reduce the temperature effect significantly at temperatures above $40^{\circ} \mathrm{C}$, compared with the FHP model. For temperatures below $20^{\circ} \mathrm{C}$ the factor $K_{l}$ has been halved to $700 \mathrm{~J} / \mathrm{mol} /{ }^{\circ} \mathrm{C}$, compared with the FHP model in order to capture the behaviour below $10{ }^{\circ} \mathrm{C}$ correctly.

For mix E, based on slag cement CEM III/B $42.5 \mathrm{~N}$, the alternative model, suggested in Table 1, is mainly governed by the observed behaviour below $20^{\circ} \mathrm{C}$ (Figure 1). Furthermore, the apparent activation energy $E_{a 20}=40000 \mathrm{~J} / \mathrm{mol}$ corresponds to what has been suggested by others [3] for slag cements and the value $K_{2}=200 \mathrm{~J} / \mathrm{mol} /{ }^{\circ} \mathrm{C}$ ensures that the rate factor at high temperatures is not overpredicted significantly. It is seen from Figure 3 that the alternative model suggested for $T$ $>20^{\circ} \mathrm{C}$ is almost identical with the original FHP model despite different parameters.

Table 1 - Apparent activation energy model parameters used in the alternative models shown in Figures 1-3. See also Figure 1 and Figure 2 in Part 1 of this article.

\begin{tabular}{ccccc}
\hline $\begin{array}{c}\text { Mix } \\
\mathrm{ID}\end{array}$ & $E_{a 20}(\mathrm{~J} / \mathrm{mol})$ & $\begin{array}{c}\text { Parameters in }(8) \\
K_{1}\left(\mathrm{~J} / \mathrm{mol} /{ }^{\circ} \mathrm{C}\right)\end{array}$ & $K_{2}\left(\mathrm{~J} / \mathrm{mol} /{ }^{\circ} \mathrm{C}\right)$ & \\
\hline $\mathrm{A}-\mathrm{D}$ & 33500 & 700 & 300 & Figures 1-2 \\
\hline $\mathrm{E}$ & 40000 & 1800 & 200 & Figures 1 and 3 \\
\hline $\begin{array}{c}\text { Original FHP- } \\
\text { model }\end{array}$ & 33500 & 1470 & 0 & Figures 1-3 \\
\hline
\end{tabular}


Nordic Concrete Research - Publ. No. NCR 62 - ISSUE 1 / 2020 - Article 6, pp. 107-124
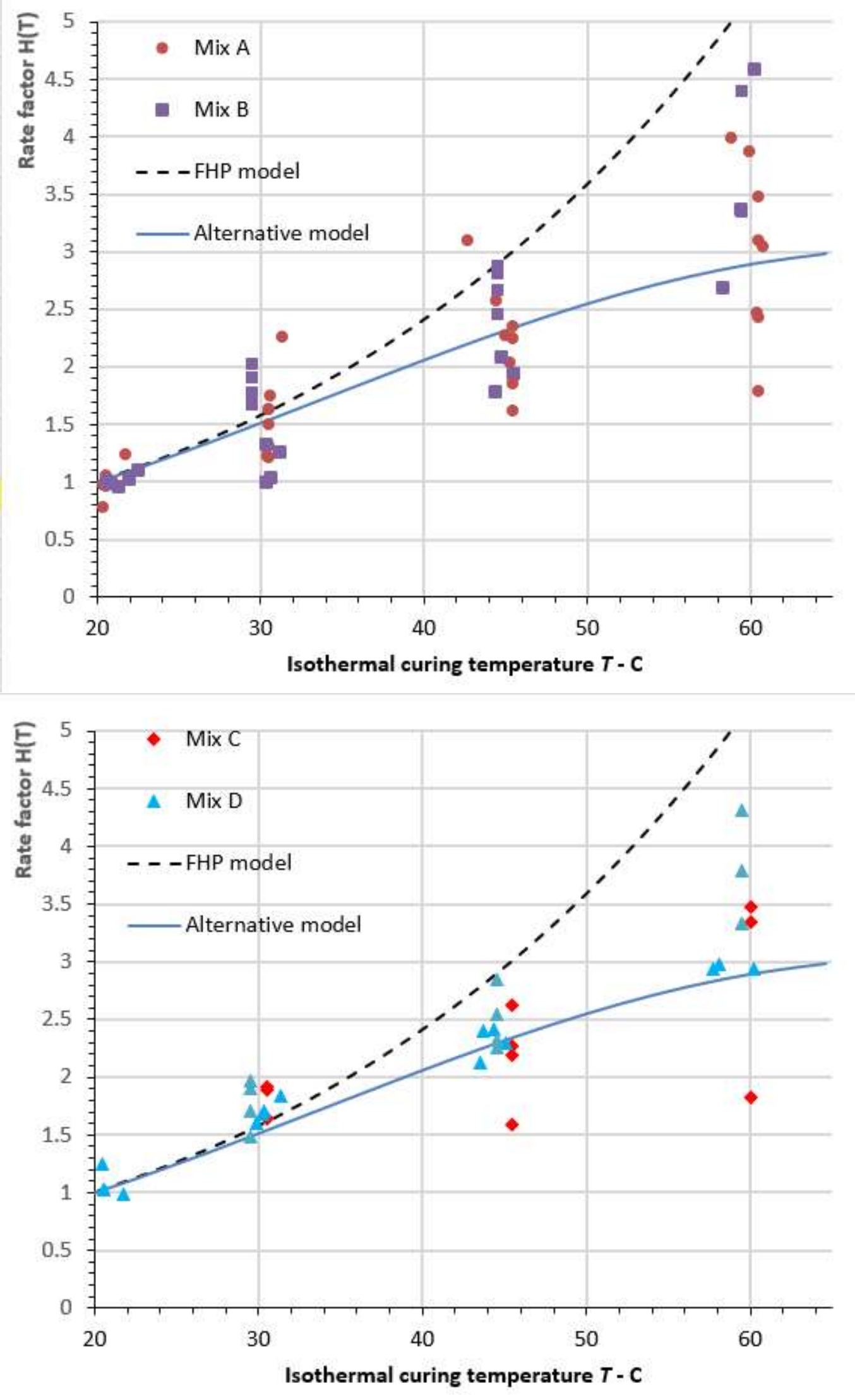

Figure 2 - Rate factor $H_{\text {test }}(T)$ for concrete mixes $A, B, C$ and $D$. 


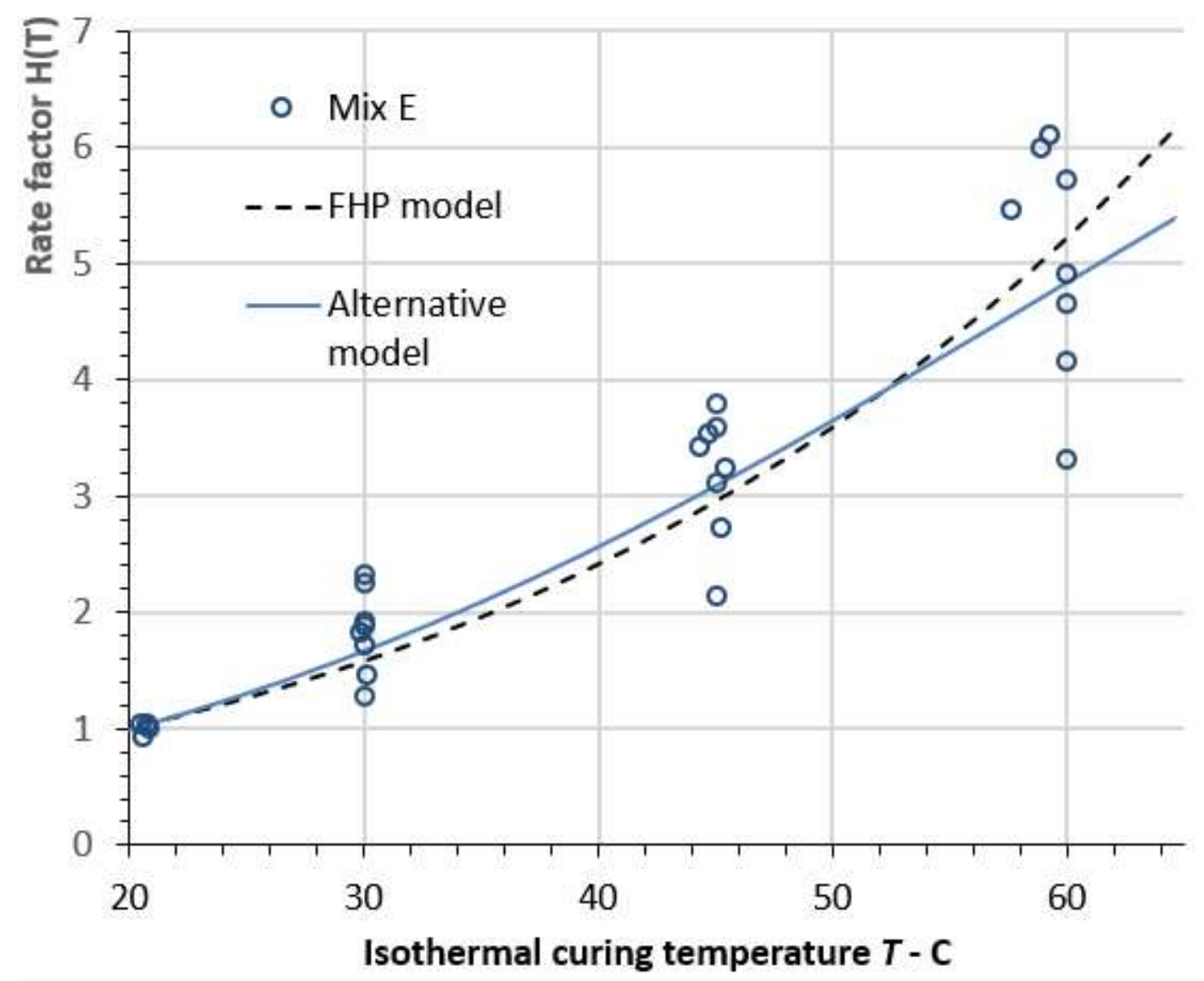

Figure 3 - Rate factor $H_{\text {test }}(T)$ for concrete mix $E$.

In Figures 4-6, the strength results are depicted as a function of the maturity age for all the tests, applying the alternative model parameters given in Table 1 . The reference strength model given in Part 1 is shown by the solid lines. When comparing Figures 4-6 with the strength versus age diagrams in Annex A in Part 1, the ability of the suggested maturity model to gather the results in a narrow band around the reference strength curve is clearly seen. However, when the maturity age increases above 7 to 10 days the accuracy becomes poorer and especially for the higher curing temperatures the maturity model overpredicts the later-age strengths. This is a result of the crossover effect that was discussed in Part 1 and further treated later in Part 2.

\section{2}

\section{Accuracy of the suggested alternative model}

In order to assess the accuracy of the model parameters suggested above, Table 2 contains the average ratios between the modelled compressive strengths divided by the measured ones for each combination of temperature and maturity. Table 2 contains the assessment of accuracy for both the FHP model and for the alternative model suggested in Table 1 for all the concrete mixes. For each concrete the combinations of the curing temperature $T$ and the real age $t$ at testing are used to determine the maturity age $M(T, t)$. To do so the model parameters given in Table 1 are inserted into (1) and applied into the equations (P1-2) and (P1-4) of Part 1. 
Nordic Concrete Research - Publ. No. NCR 62 - ISSUE 1 / 2020 - Article 6, pp. 107-124
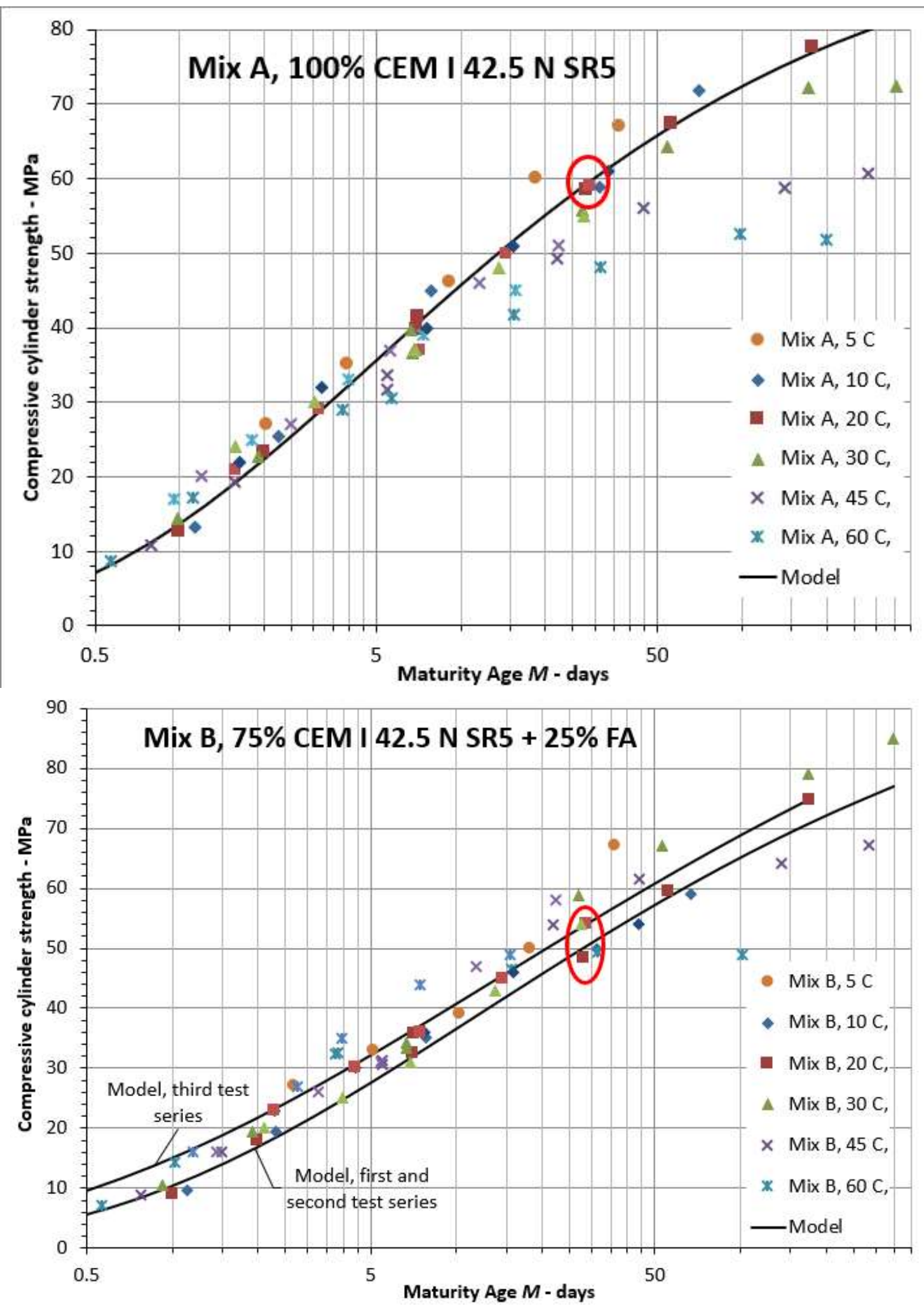

Figure 4 - Measured compressive strengths as a function of $M$ for mix $A$ and mix $B$. The red circles indicate the 28-days reference strength. 
Nordic Concrete Research - Publ. No. NCR 62 - ISSUE 1 / 2020 - Article 6, pp. 107-124

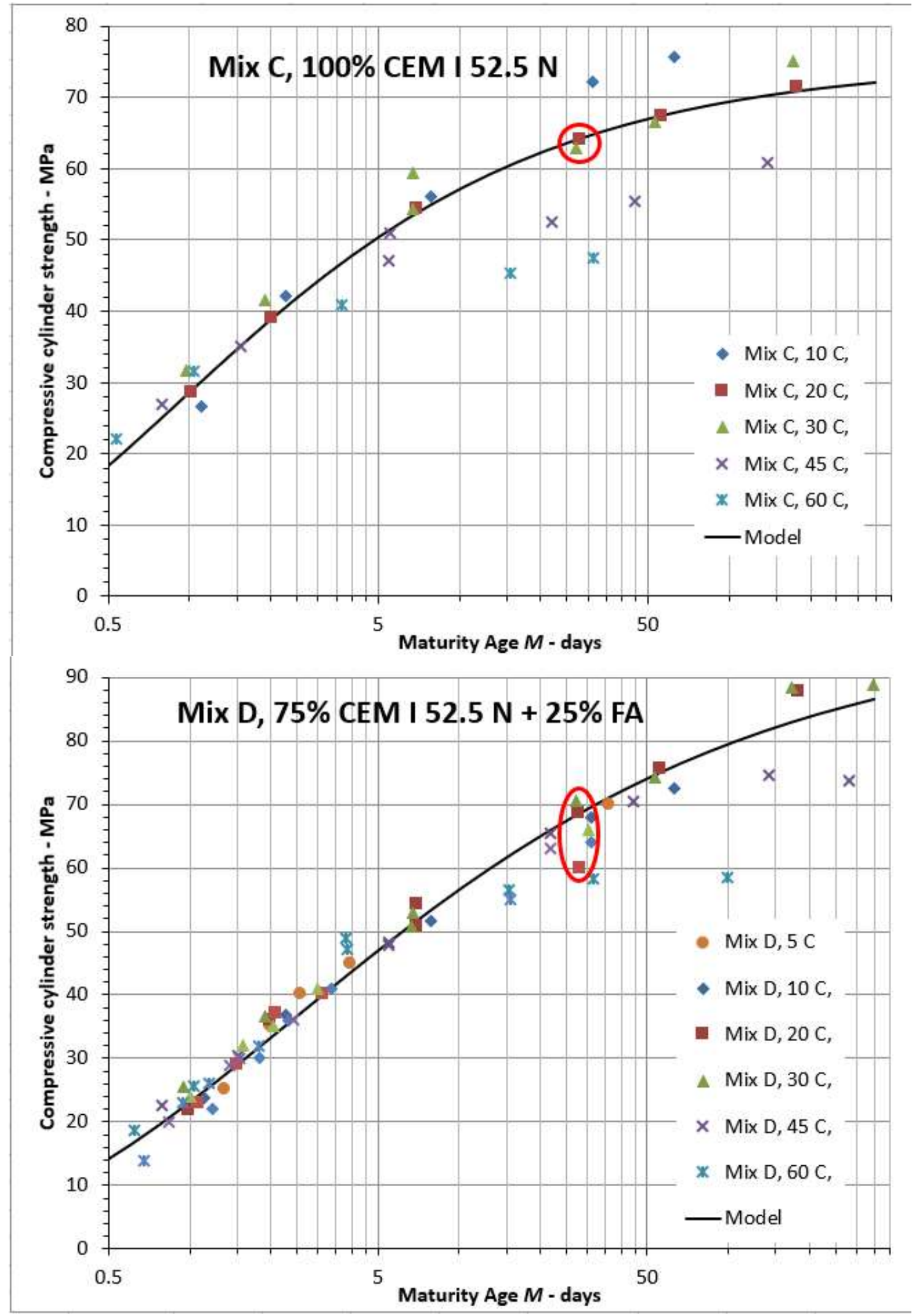

Figure 5 - Measured compressive strengths as a function of $M$ for mix $C$ and mix $D$. The red circles indicate the 28-days reference strength value. 
Nordic Concrete Research - Publ. No. NCR 62 - ISSUE 1 / 2020 - Article 6, pp. 107-124

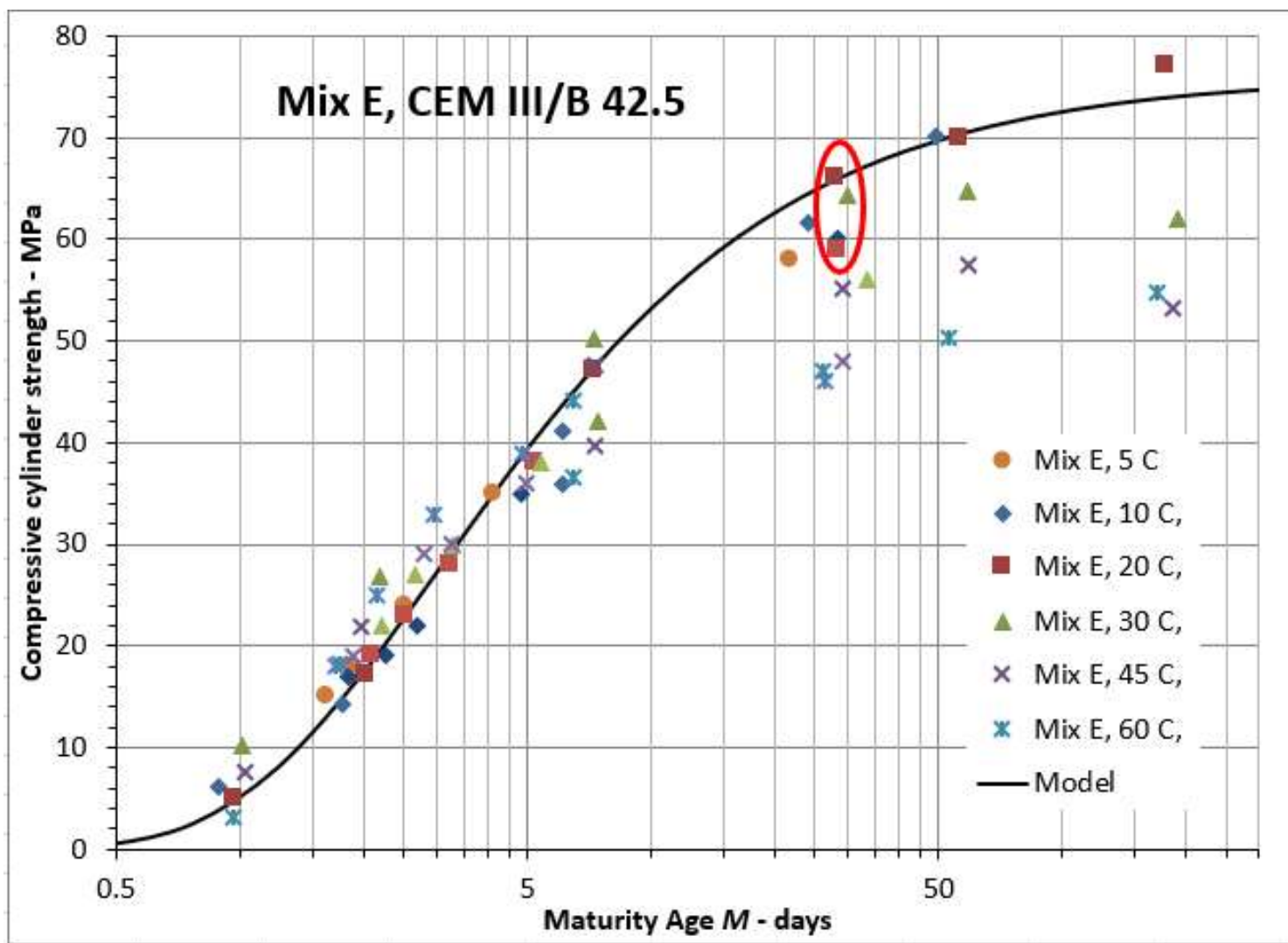

Figure 6-Measured compressive strengths as a function of $M$ for mix E. The red circle indicates the 28-days reference strength value.

Table 2 - Ratios between Modelled and Measured compressive strength values for the curing times up to approximately 10 maturity days. All curing temperatures except $20^{\circ} \mathrm{C}$ are included. Corresponds to the data in Figures 1-3 and model parameters in Table 1.

\begin{tabular}{ccccc}
\hline Mix & \multicolumn{2}{c}{ FHP model (P1-3) } & \multicolumn{2}{c}{ Alternative model (1) } \\
ID & Average & $\begin{array}{c}\text { Standard } \\
\text { deviation }\end{array}$ & Average & $\begin{array}{c}\text { Standard } \\
\text { deviation }\end{array}$ \\
\hline A & 1.08 & 0.213 & 0.98 & 0.111 \\
B & 1.06 & 0.151 & 0.96 & 0.120 \\
C & 1.07 & 0.130 & 0.99 & 0.088 \\
D & 1.06 & 0.170 & 0.98 & 0.081 \\
E & 1.02 & 0.245 & 0.96 & 0.188 \\
\hline
\end{tabular}

Normally for safety reasons one would like the model strength predictions to be slightly lower than the actual measured strengths. This is ensured by the suggested alternative models as it is seen in Table 2. The FHP model tends to overestimate the early-age strength which is generally yielding slightly unconservative predictions. Furthermore, Table 2 also shows that the standard deviation is generally lower for the alternative model suggestion than for the original FHP model. However, it is also seen from Table 2 that for mix E (slag cement) the scatter is higher than for the other concrete types. This could indicate that the slag cement concrete is more difficult to model accurately, and that the simple bi-linear model is not sufficiently advanced. It is also seen that the FHP model and the alternative model yield almost the same overall precision for mix E, 
but this is mainly because the FHP model overpredicts the rate factor for low temperatures and vice versa. Hence, on average the FHP model performs well but not on the individual results.

There are no indications that the concretes containing fly ash are significantly different from the concretes with OPC when it comes to modelling of the maturity.

\subsection{Effect of curing temperature on the later-age strengths}

The effect of the iso-thermal curing temperature on the later-age strengths, is clearly seen in Figures 4-6. For mix $\mathrm{A}$ it is seen that at 45 and $60^{\circ} \mathrm{C}$, the strength development after 10 maturity days levels off from the reference curve. Hence, the maturity model overpredicts the strength significantly within this range. For $60^{\circ} \mathrm{C}$ the long-term strength does not even reach the 28 day reference strength. When fly ash is added in mix B (Figure 4 bottom) this effect has almost disappeared, which is probably because of the effect of the fly ash in the early hydration process where it creates space for the hydration products and slows down the rate of hydration. However, this implies also that the strengths are generally lower for mix B than for mix A (about 5 to $10 \mathrm{MPa}$ ). Generally, the addition of fly ash to concrete is known to result in a significant strength increase beyond the age of 28 days which is also clearly seen for mixes B and D, respectively in Figure 4 and Figure 5 .

For mix C and mix D a similar effect of the fly ash is seen in Figure 5. For mix E the strength reduction already starts at $30^{\circ} \mathrm{C}$ and for 45 and $60^{\circ} \mathrm{C}$ the effect is pronounced already after 5 to 7 maturity days (Figure 6). Hence, the slag cement seems to be very sensitive against curing at high temperatures, showing a very significant cross-over effect for the later-age strengths.

Generally, it is seen that the strength development measured at curing temperatures above $45^{\circ} \mathrm{C}$ begins to deviate from the maturity model when it reaches strength levels of 50 to $60 \%$ of the 28 days reference strength. In a recent Swedish investigation from Luleå University [4] a model was suggested to capture the cross-over effect and the strength reduction as a function of the curing temperature. They divide the hydration process into three phases corresponding to the fresh state, the finishing period until the strength is about $0.5 \mathrm{MPa}$ and finally the third phase where the strength increases towards its final level. The first two phases are generally difficult to measure because the experimental scatter on the strength becomes too high. In the present test series, the earliest compressive strengths were determined at about 4 to 6 hours after casting (see Annex A and B in Part 1). It is outside the scope of the present article to model the cross-over effect. However, in the following section a small investigation is described, aiming to explain the reason for the observed later-age strength reduction at high temperature curing conditions.

\section{$2.4 \quad$ Supplementary tests}

In order to better understand the effect of high temperature curing, the third series of tests included some supplementary tests [5]. Instead of placing the newly cast test samples in the hot water bath right after casting they were subjected to a slow gradual increase in temperature during the first day until demoulding. This procedure was chosen to represent the real temperature history inside the central part of a massive casting. The hypothesis was that the abrupt exposure to high curing temperature at the very beginning of the hydration process would have a damaging effect on the hydration products, causing the reduced long-term strengths reported above. 
Nordic Concrete Research - Publ. No. NCR 62 - ISSUE 1 / 2020 - Article 6, pp. 107-124
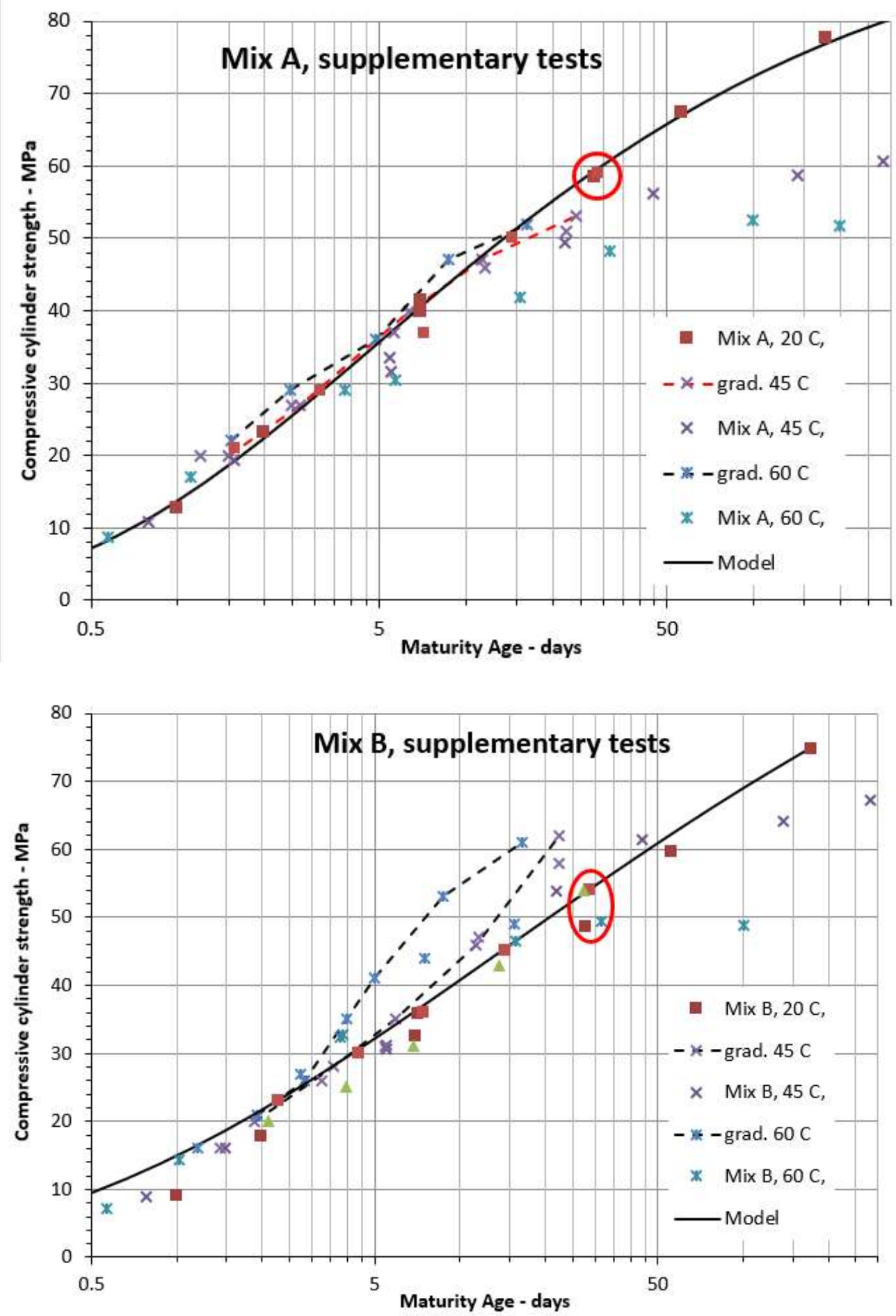

Figure 7 -Measured compressive strengths as a function of $M$ for mix $A$ and mix $B$.

Once the samples had reached the planned peak temperature in the climate-controlled chamber, they were demoulded and placed in the water bath at either 45 or $60^{\circ} \mathrm{C}$ for the rest of the curing period. Tests were planned to reach a maturity of approximately 28 days following the FHP model. It was found that the strengths obtained, following the gradually increasing temperature history, were 10 to $20 \%$ higher than the strengths obtained after iso-thermal curing at high temperature [5]. Hence, the hypothesis seems to be confirmed. 
Nordic Concrete Research - Publ. No. NCR 62 - ISSUE 1 / 2020 - Article 6, pp. 107-124

In Figures 7 and 8, the results from the gradually increased temperature history are included together with the iso-thermal curing results for 45 and $60^{\circ} \mathrm{C}$. The reference strength development is also shown for comparison. The results from the gradually increased temperature tests are connected by dashed lines and the iso-thermally cured ones are symbols without lines.
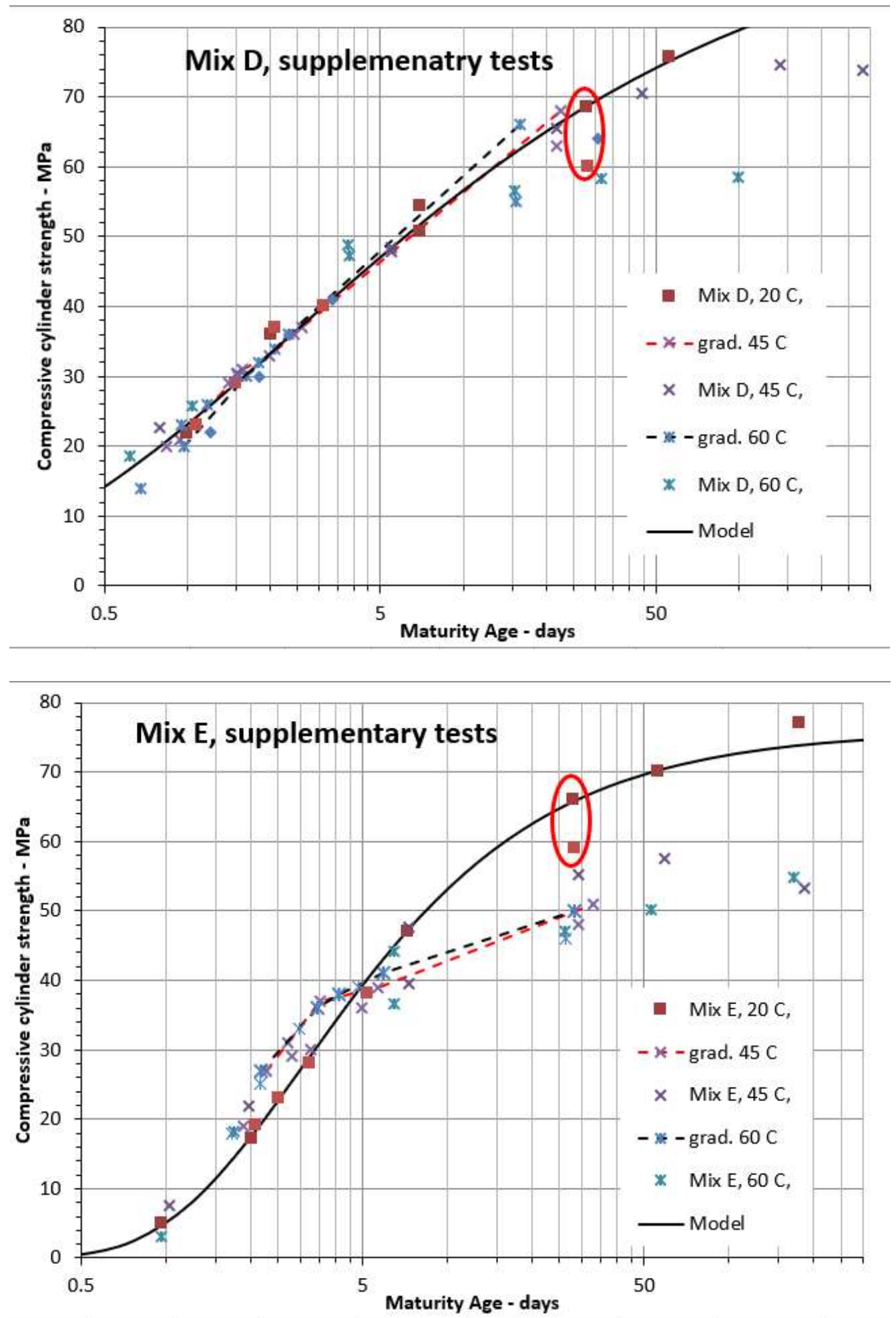

Figure 8 -Measured compressive strengths as a function of $M$ for mix $D$ and mix $E$. 
The results show that the for mixes A and D there is a positive effect on the strength for $60^{\circ} \mathrm{C}$. For the $45^{\circ} \mathrm{C}$ the effect is less pronounced. For mix B in Figure 7 the results look peculiar as it seems that the strengths increase with the maturity at a much higher rate than expected. The results from mix B tests are not considered to be trustworthy and should be validated further before any conclusions are drawn.

For mix E the gradually increased temperature does not alter the behaviour and the later -term strength both at 45 and $60^{\circ} \mathrm{C}$ is on the same level as for the iso-thermally cured samples.

Hence, the supplementary tests seem to support the hypothesis given above but there is an obvious need for further research on this topic.

Furthermore, the modelling of temperature related cracking in massive structures is known to be strongly dependent on a precise maturity model $[4,9,10]$ that covers the full range of temperatures to be expected inside a massive concrete structure. From the observations in the present test series it is concluded that further research is needed on the temperature effects on the later-age strengths and the cross-over effect. At present the strength reduction experienced at higher curing temperatures above $45^{\circ} \mathrm{C}$ is normally not included in the modelling tools available. This could mean that the early-age temperature related risk of cracking is modelled in an unconservative manner for the inner parts of a massive cross-section.

\section{COMPARISONS WITH OTHER TESTS}

\subsection{Danish investigation from Horsens Engineering School (DK)}

A similar Danish investigation was reported in 2013 from the concrete laboratory of the engineering school in Horsens (DK). Three different concretes were tested in the laboratory [7] at different ages and different temperatures $\left(20,35,50\right.$ and $\left.70^{\circ} \mathrm{C}\right)$. The three concretes were made with the same cement type as in mix C and mix D (see Table 1 in Part 1) previously reported herein. The binder compositions were as follows:

- $\quad$ Mix H-A: 100\% CEM I $52.5 \mathrm{~N}, \mathrm{w} / \mathrm{c}=0.42($ similar to mix C)

- Mix H-B: $85 \%$ CEM I $52.5 \mathrm{~N}+15 \% \mathrm{FA}$, w/c $=0.42$ (similar to mix D but with smaller amount of fly ash)

- Mix H-C: $78 \%$ CEM I $52.5 \mathrm{~N}+22 \% \mathrm{FA}, \mathrm{w} / \mathrm{c}=0.72$.

Mix $\mathrm{H}-\mathrm{C}$ is a common low strength concrete for indoor applications where no durability concerns exist. The compressive strength was measured at different ages during the iso-thermal curing conditions. Furthermore, the electrical conductivity was measured according to the ASTM test method C1760. Only the strength results are presented herein. For each combination of age and curing temperature a single specimen was tested due to restrictions in time and resources. Hence, the data presented in Figure 9 and Figure 10 are individual strength values.

The maturities depicted in Figure 9 and Figure 10 correspond to (1) with the input values $E_{a 20}=$ $33500 \mathrm{~J} / \mathrm{mol}$ and $K_{2}=300 \mathrm{~J} / \mathrm{mol} /{ }^{\circ} \mathrm{C}$, c.f. Table 1 . The fit is not as convincing as seen before and it could be argued that the $E_{a 20}$ value is too high for mix H-A and mix H-B. For the low strength concrete mix H-C the model fits the data satisfactory except for the highest curing temperature (Figure 10). 
Nordic Concrete Research - Publ. No. NCR 62 - ISSUE 1 / 2020 - Article 6, pp. 107-124
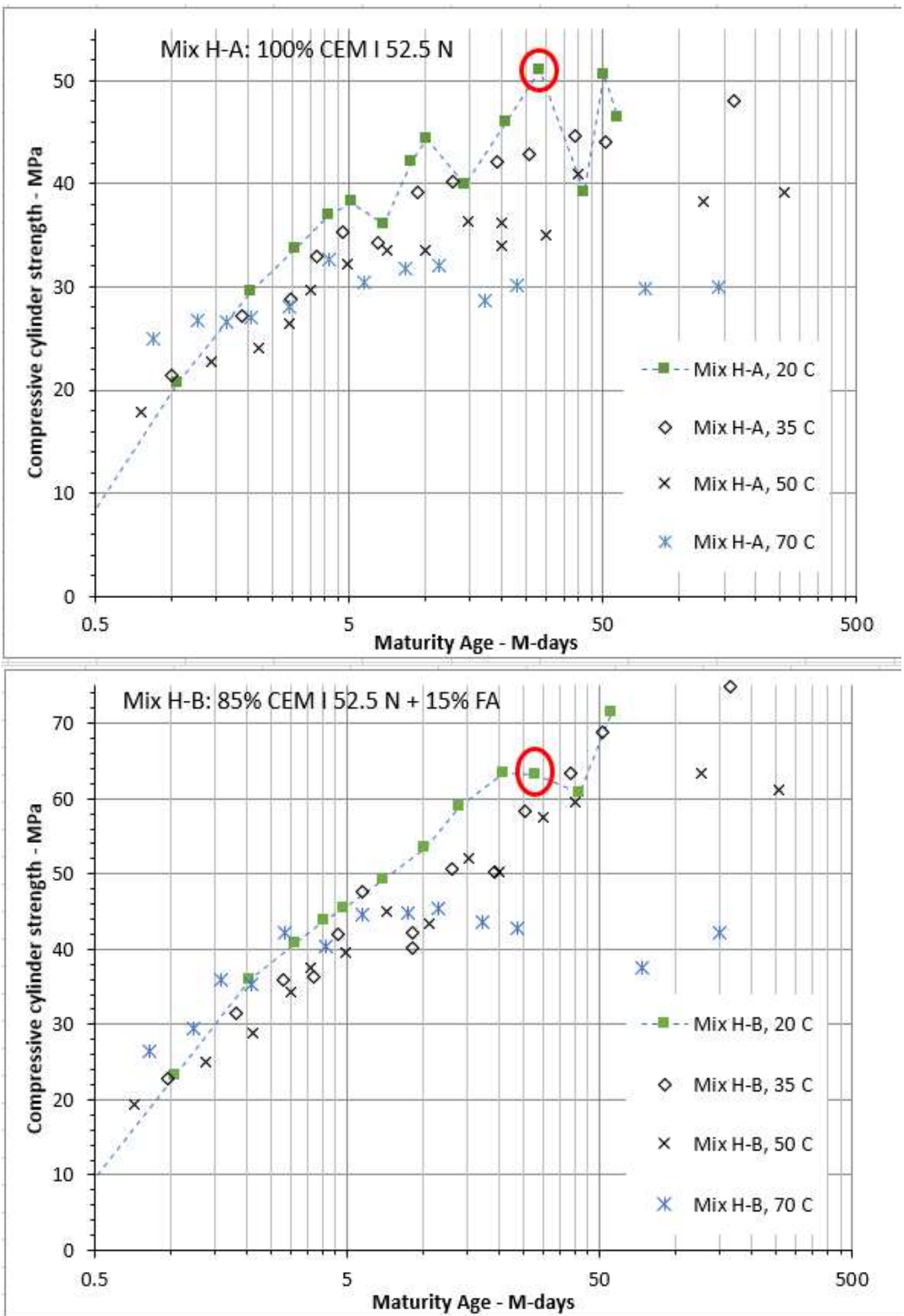

Figure 9 -Measured compressive strengths as a function of $M$ for mix $H-A$ and mix $H-B$ [7]. The red circles indicate the 28-days reference strength. 
Nordic Concrete Research - Publ. No. NCR 62 - ISSUE 1 / 2020 - Article 6, pp. 107-124

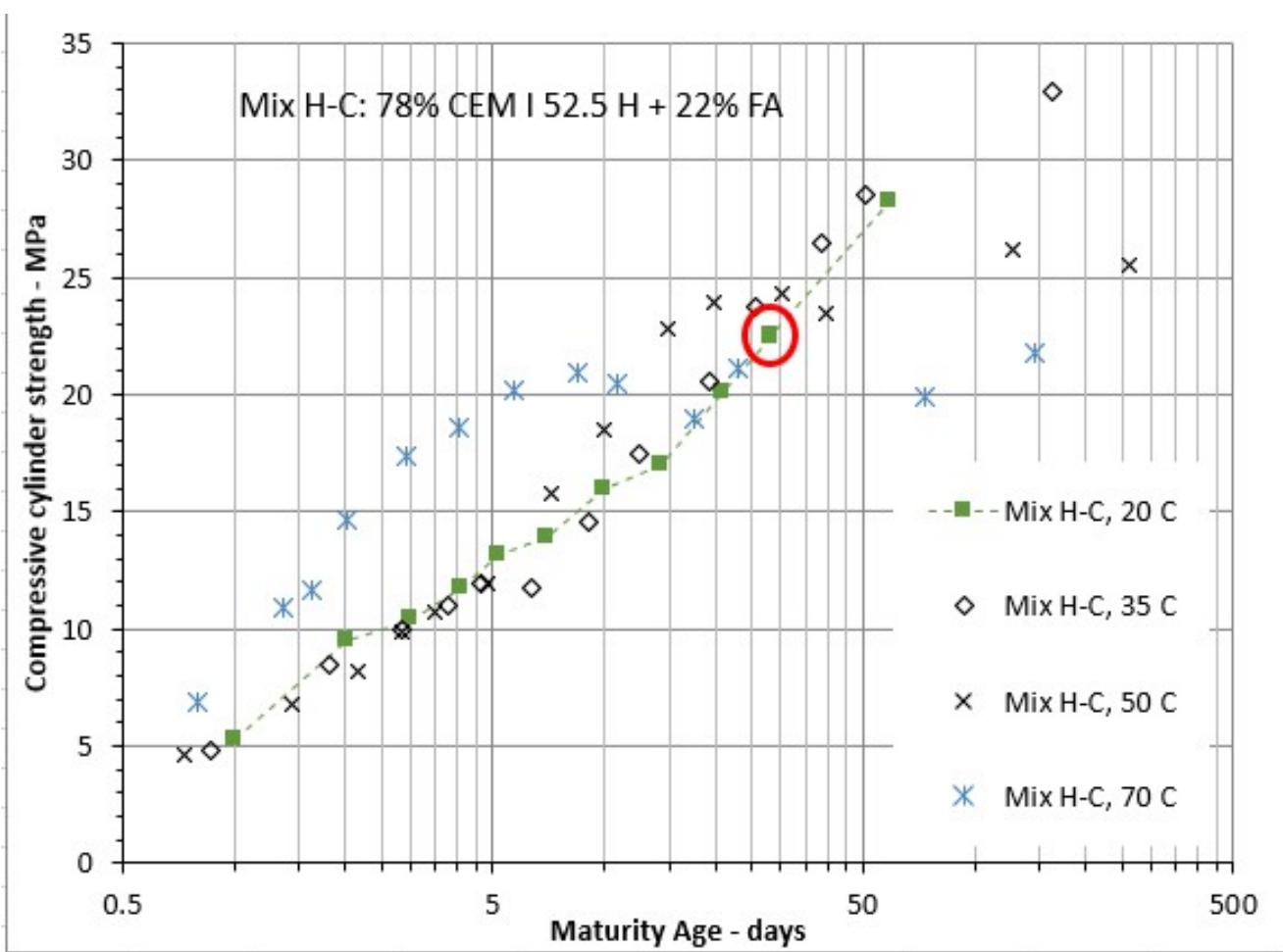

Figure 10-Measured compressive strengths as a function of $M$ for low strength concrete mix $H-C$ [7]. The red circle indicates the 28-days reference strength.

Especially for mix H-A significant scatter is seen for the reference temperature as the maturity age reaches 14 days and above. This could probably have been avoided if more than a single sample had been used. For mixes $\mathrm{H}-\mathrm{A}$ and $\mathrm{H}-\mathrm{B}$ the $70^{\circ} \mathrm{C}$ curing conditions resulted in a significant long-term strength reduction compared with the 28 -days reference value (Figure 9 ). At $50^{\circ} \mathrm{C}$ the strength reduction is smaller, and the use of fly ash seems to counter-act the later-age strength reduction somewhat. This was also observed for the mixes in the previous section.

For mix $\mathrm{H}-\mathrm{C}$ the suggested alternative model fits the results up to curing temperature $50^{\circ} \mathrm{C}$ as it is seen in Figure 10 . However, the $70^{\circ} \mathrm{C}$ results indicate that the suggested maturity model is too conservative for very high curing temperatures. Moreover, such high temperature curing conditions are normally not realistic for low-strength concrete types like mix H-C.

\section{2}

\section{Swedish investigation from Luleå University}

In 2011 a Swedish research report, containing measurements of compressive strength as a function of curing temperature and age, was released. The results were reported in an article in 2012 [4] describing a new maturity model for Swedish cement types. This investigation has been referred to previously in this article. Five different concretes with w/c ranging from 0.70 down to 0.38 were tested. Furthermore, two different cement types normally used in Sweden were used (CEM II/A-LL 42.5 R typically used for general purpose concretes and CEM I 42.5 N SR-3 typically used for civil engineering structures).

Curing temperatures of 20,35 and $50^{\circ} \mathrm{C}$ were applied and the compressive strengths were tested at ages up to 2 days. Hence, only the very early-age results (up to about 5 maturity days) were reported in [4]. The apparent activation energy is fitted to the results, yielding a constant value of 
$22864 \mathrm{~J} / \mathrm{mol}$, for all the tested concretes. No temperature dependency of the apparent activation energy was reported (hence, $\kappa=0$ in (P1-5)). Comparing this $E_{a}$ value with Figure 1 from Part 1 it is seen that it corresponds with the Norwegian model suggested in [2] but lower activation energy than what has been observed in the present article.

For the cement type CEM II/B-LL, a significant strength reduction was observed compared with the reference strength curve. For $50^{\circ} \mathrm{C}$ curing temperature the strength reduction was almost $50 \%$. For the CEM I $42.5 \mathrm{~N} \mathrm{SR}-3$ this reduction was not observed but it should be kept in mind that the results only range up to about 5 maturity days, making it difficult to conclude anything on the later-age strength behaviour.

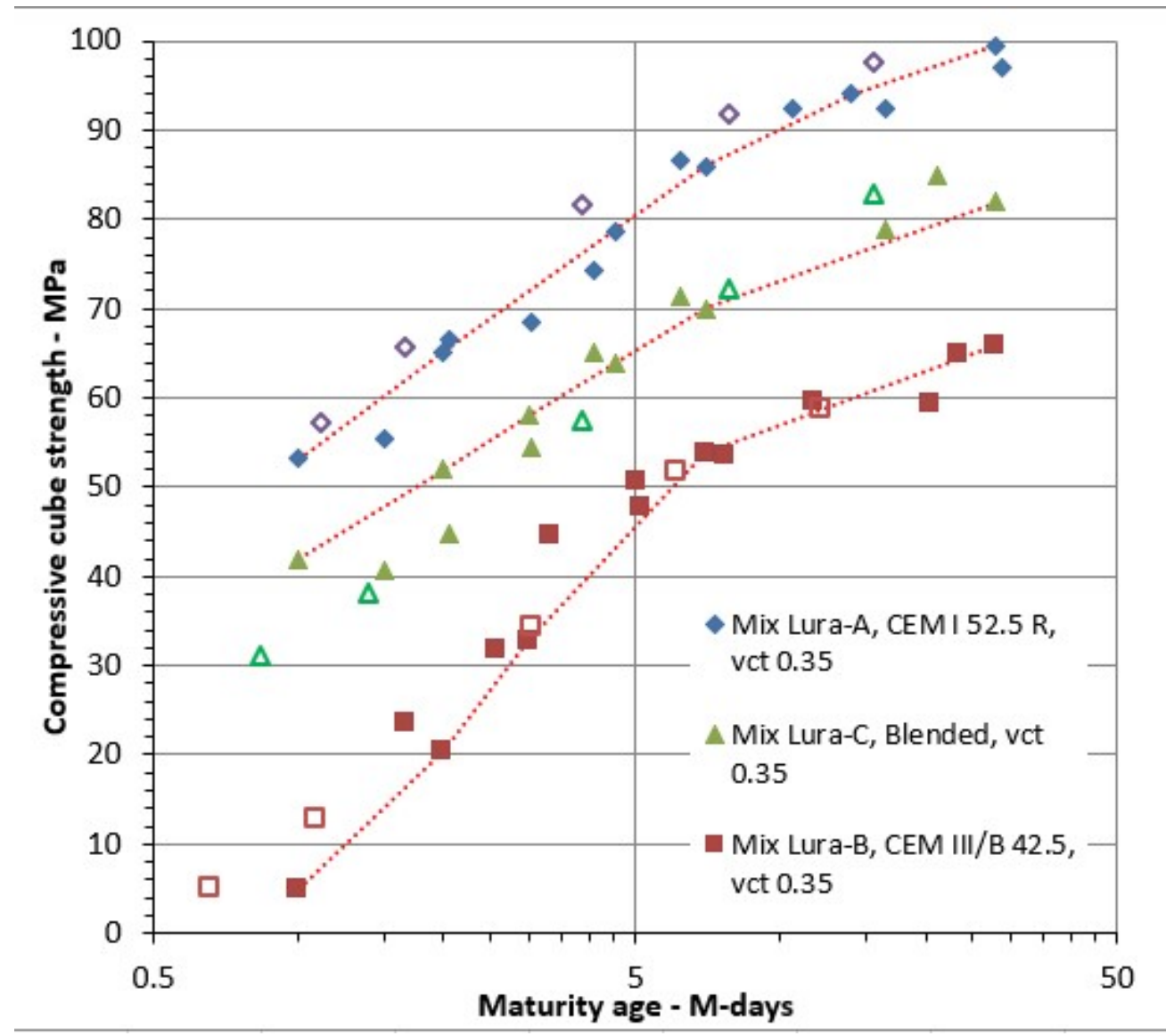

Figure 11 - Measured compressive strengths (150 mm cubes) as a function of the maturity age, iso-thermally cured at 10,20, 30 and $40^{\circ} \mathrm{C}$ [8]. The red dashed lines indicate the reference strength development at $20^{\circ} \mathrm{C}$. The open symbols represent results cured at $10^{\circ} \mathrm{C}$.

\subsection{Investigation from Delft University of Technology}

Lura et al. [8] investigated the effects of temperature on the early-age shrinkage of high-performance concretes. Three different concrete mixes were tested, each having $\mathrm{w} / \mathrm{c}$ ratio of 0.35 (water to cementitious material ratio), based on three different binder compositions:

- Mix Lura-A: $475 \mathrm{~kg} / \mathrm{m}^{3}$ CEM I $52.5 \mathrm{R}$.

- Mix Lura-B: $475 \mathrm{~kg} / \mathrm{m}^{3}$ CEM III/B 42.5 (similar to mix E)

- Mix Lura-C: Blended CEM I and CEM III/B (50 \% of each) 
For each mix there is added micro silica, corresponding to about $10 \%$ of the binder content.

Cube strengths were reported for curing temperatures of $10,20,30$ and $40^{\circ} \mathrm{C}$. Only maturity ages up to about 28 days were included in the test series. All results are depicted in Figure 11 (average values from three test specimens). For mix Lura-B the maturity model in Table 1 for mix E (slag cement) is applied and for the two other concretes the model for mix A-D is applied. It is seen that there is good correspondence between the model and the measurements. In order to obtain a perfect fit all the results should be on the red dashed line. Only for mix Lura-C it seems that the model overpredicts the early-age strengths somewhat.

\section{CONCLUSIONS}

The article presents Danish test results for five different concretes, applying different binder compositions (CEM I 42.5 N SR-5 and CEM I 52.5 N with and without fly ash; CEM III/B 42.5 N). Part 1 of the article describes the maturity concept for concrete with focus on the Freiesleben Hansen Pedersen (FHP) model which is widely used. Part 1 also describes the experimental program, the test results and the five mix designs applied. In Part 2 of the article the compressive strength results obtained at different curing temperatures are used to suggest a modification of the FHP model. Only concretes with w/c ratios around 0.40 and air entrainment have been tested at different curing temperatures in the present investigation.

The following main conclusions are made regarding the observed compressive strengths and the maturity modelling:

1. The original FHP model, suggesting a temperature dependent apparent activation energy for temperatures below the reference temperature $20^{\circ} \mathrm{C}$ and constant activation energy above $20^{\circ} \mathrm{C}$, is inadequate to model different cement types and binder compositions.

2. The original FHP model generally overpredicts the early-age compressive strengths (up to about 10 maturity days). The higher the temperature the larger the overprediction.

3. The maturity model applied in Eurocode 2 and in the fib Model Code is based on the apparent activation energy in the original FHP model but without any temperature dependency at all. This will overpredict the early-age strengths significantly, especially for cold curing conditions (below $10^{\circ} \mathrm{C}$ ).

4. An alternative formulation of the bi-linear maturity model is proposed to ensure a better fit between the laboratory test and the maturity model for early-age compressive strengths. The new model suggests a decreasing apparent activation energy with temperature - both below and above the reference temperature.

5. For later-age strengths (beyond 7 to 10 maturity days) a significant strength reduction is observed for curing temperatures above $45^{\circ} \mathrm{C}$. Hence, the use of the maturity model to determine later-age strength predictions, is connected with substantial inaccuracy, especially for higher curing temperatures. The strength reduction is most severe for the concretes without fly ash addition. The slag cement concrete (CEM III/B 42.5 N) also shows substantial later-age strength reductions.

6. The newly suggested maturity model is compared with reported test results found in the literature and a reasonable correlation is found for early-age strengths.

7. The apparent activation energy is found to be subject to significant experimental scatter. Even a small deviation in the measured strength may result in huge differences in the apparent activation energy. 
There is increased need for modeling and forecasting the early-age strength development of concrete in the field. New technologies are emerging, and real-time temperature monitoring is being used to determine the right time for removal of formwork, curing requirements, prestressing, etc. Therefore, it is important that the maturity model, applied to convert the combined temperature and age history into equivalent age (maturity), is accurate and provides trustworthy model forecasts which are slightly conservative. The model parameters presented here are one step in that direction.

\section{REFERENCES}

1. Freiesleben Hansen P \& Pedersen E J: "Måleinstrument til control af betons hærdning" "Maturity Computer for Controlled Curing and Hardening of Concrete"). Nordisk Betong, No. 1, 1977, pp. 21-25, (in Danish).

2. Kanstad T, Hammer T A, Bjøntegaard Ø \& Sellevold E J: "Mechanical properties of young concrete: Part I Experimental results related to test methods and temperature effects". $M a$ terials and Structures, Vol. 36, 2003, pp. 218-225.

3. Schindler A K: "Effect of temperature on hydration of cementitious materials". ACI Materials Journal, Vol. 101, No. 1, 2004, pp. 72-81.

4. Fjellström P, Jonasson J E, Emborg M \& Hedlund H: "Model for concrete strength development including strength reduction at elevated temperatures". Nordic Concrete Research, No. 45, 2012, pp. 25-44.

5. Aarre T \& Kaasgaard M: "Influence of curing temperature on strength development of concrete". Key Engineering Materials, Vol. 711, 2016, pp. 118-125.

6. Kjellsen K O \& Detwiler R J: "Later-age strength prediction by a modified maturity method". ACI Materials Journal, Vol. 90, No. 3, 1993, pp. 220-227.

7. Normann Munch-Petersen G \& Munch-Petersen C: "Betons tidlige egenskabsudvikling som funktion af temperature" "“Concrete early-age property development as function of the curing temperature”). Via University College, Horsens, Denmark, 2013, 38 pp. (In Danish).

8. Lura P, van Breugel K \& Maruyama I: "Effect of high temperature and type of cement on early-age shrinkage of high-performace concrete". Cement and Concrete Research, Vol. 31, 2001, pp. 1867-1872.

9. Maruyama I \& Lura P: "Properties of early-age concrete relevant to cracking in massive concrete". Cement and Concrete Research, Vol. 123, 2019, pp. 1-12.

10. Nielsen C V: "Modeling the heat development of concrete associated with cement hydration". Special Publication ACI SP-241, Concrete heat development: Monitoring, prediction and management, American Concrete Institute, Farmington Hills, MI, USA, 2007, pp. 95 109. 